\title{
Self-feeding behavior changes induced by a first and a second generation of domestication or selection for growth in the European sea bass, Dicentrarchus labrax
}

\author{
Sandie Millot ${ }^{1, \text { a }}$, Samuel Péan ${ }^{1}$, Béatrice Chatain ${ }^{2}$ and Marie-Laure Bégout ${ }^{1}$ \\ 1 Ifremer, Place Gaby Coll, BP 7, 17137 L'Houmeau, France \\ 2 Ifremer, Station expérimentale d'aquaculture, chemin de Maguelone, 34250 Palavas-les-Flots, France
}

Received 25 November 2010; Accepted 4 February 2011

\begin{abstract}
Among the strategies that can be used to improve fish welfare in a rearing environment, domestication and/or selective breeding was proposed to minimize fish responsiveness to husbandry practices. To verify this hypothesis on a recently domesticated species, the sea bass Dicentrarchus labrax, two experiments were realized, each using two populations differing according to their level of domestication or selection. For the first experiment, we used one population produced from wild parents (Wild; initial body mass: $106 \pm 3 \mathrm{~g}$ ), and one population from parents selected for growth for one generation (Selected 1; initial body mass: $129 \pm 4 \mathrm{~g}$ ). For the second experiment, we used one population produced from parents domesticated for two generations (Domesticated; initial body mass: $72 \pm 3 \mathrm{~g}$ ), and one produced from parents selected for growth for two generations (Selected 2; initial body mass: $89 \pm 4 \mathrm{~g}$ ). The first experiment was carried out over 112 days with 240 fish (60 fish per tank, 120 fish per population), and the second one over 84 days with 200 fish (50 fish per tank, 100 fish per population). Two variables, self-feeding behavior and growth performance, were measured over the time of the experiments. After a control period, the fish were submitted twice, at three-week intervals, to an acute stress treatment consisting of draining the tank and leaving the fish out of water for one minute. Both self-feeding behavior and growth performance were altered by the acute stress treatment. During the first post-stress period, the Domesticated and Selected ( 1 and 2) groups showed more pronounced post-stress exposure responses than the Wild fish: they modified their feeding rhythm, their feed intake, and their growth rate. During the second post-stress period, feeding rhythm was still affected (being more diurnal with a well defined peak), but the feed intake and growth rate results showed that the Domesticated and Wild groups seemed less affected than Selected ( 1 and 2) populations, which continued to express a high post-stress response.

According to these results, it can be concluded that: (1) an application of two acute stress treatments, at three-week intervals, modified fish feeding behavior and growth performance; (2) the domestication process seemed to improve fish adaptation abilities to this kind of stress; and (3) the process of selection for growth led to a final, better growth, but did not seem to improve fish acute stress tolerance.
\end{abstract}

Key words: Feed intake / Feeding rhythm / Specific growth rate / Adaptation capacities / Fish welfare

\section{Introduction}

Fish domestication can be defined as "the process by which a population of animals becomes adapted to humans and to the captive environment, by some combination of genetic changes occurring over generations and environmentally induced developmental events re-occurring during each generation" (Price 1984). Selection is usually applied to improve traits strongly associated with production cost (e.g., growth rate, disease resistance, age at maturity and flesh quality), and very little is known on selected fish capacities to tolerate stress. Nevertheless, fish responsiveness to stress was shown to have

a Corresponding author: sandiemillot@yahoo.fr a distinct genetic component, and may therefore be modified by selective breeding (Pottinger and Pickering 1997). Thus, it may be feasible to generate strains displaying high stress tolerance and therefore improve performance within aquaculture across a number of traits (e.g., improvement of feed conversion efficiency, growth, fecundity, egg quality, post-slaughter flesh quality, and reduction in the incidence of disease), and in addition an improvement of their welfare (Pottinger and Pickering 1997).

Alongside these improvement and perhaps partly due to the rapid expansion of the aquaculture industry, the welfare of farmed fish has received increasing attention. However, the concept of welfare is complex and difficult to define, although it is commonly admitted that it responds to one of the three 
following conditions: (1) the animal can adapt to its environment and is in good health, with all its biological systems working appropriately; (2) the animal is able to meet what are often called its "behavioral needs"; and (3) the animal is free of negative experiences such as pain, fear, and hunger (Huntingford and Kadri 2008). When cultured, fish are commonly exposed to repeated acute stresses that differ from those they face in the wild, such as: handling, grading, transport, and prophylactic treatment (Pottinger and Pickering 1997). Fish reaction to stress is generally divided into primary and secondary responses (Mazeaud et al. 1977), and even tertiary level responses according to Wedemeyer et al. (1990). In aquaculture, this tertiary level (Barton 2002; Conte 2004; Huntingford et al. 2006) includes both direct and indirect maladaptive effects, such as growth reduction (Barton et al. 1987; Pickering et al. 1991; Pankhurst and Van der Kraak 1997), suppressed reproductive function (Contreras-Sanchez et al. 1998; McCormick 1998, 1999; Schreck et al. 2001), and reduction in immune capacities (Einarsdottir et al. 2000), and disease resistance (Pickering 1992; Balm 1997). Therefore, even if stress responses do not reveal all welfare disturbances, it is generally accepted that they strongly indicate poor welfare (Broom 1988; Huntingford et al. 2006). Such evidence led to active research on potential methods to reduce stress responses in aquaculture species (Ashley 2007). Among these methods, domestication and selective breeding to minimize fish responsiveness to stressors has been a major research direction over the last few years (Pottinger 2003).

The European sea bass, Dicentrarchus labrax (Linnaeus 1758) is an important species in Mediterranean and Atlantic aquaculture. Sea bass was only recently domesticated, so very little is known about the effects of the early steps of domestication or selection for growth, apart from effects on the classically-measured traits of commercial interest (Dupont-Nivet et al. 2008; Vandeputte et al. 2009), and specifically, little is known about behavioral responses to stress exposure and welfare potential. The authors have already evaluated the behavioral changes induced by a first step of domestication or selection for growth in the European sea bass (Millot et al. 2010). They found that a first generation of domestication and selection improved fish growth performance, but at this early stage did not modify behavioral responses to repeated acute stress exposure (one to four acute stressor applications per day). The present study, thus proposes to evaluate and compare the effects of first and second generations of fish domestication and selection for growth on behavior changes. The chosen approach was an evaluation of the modifications induced in self-feeding (feed demand rhythm, quantities of food intake and food waste) by two acute stress exposures at an interval of three weeks (stress tolerance used as a screening procedure). Growth performance (body mass, body condition factor and specific growth rate) was recorded as a complementary trait.

\section{Materials and methods}

\subsection{Experimental set-up}

The four populations of fish tested in this experiment were produced as part of a genetic EU project to evaluate the response to selection for growth (Competus COOP-CT-2005017633). The details of rearing conditions and sizes of these populations can be found in Vandeputte et al. (2009). In summary, the four tested populations were hatched and reared at the experimental research station of Ifremer in Palavas-lesFlots (France). Until the start of the experiment, fish were reared according to usual sea bass rearing standards (Chatain 1994). All fish had been bred using full factorial designs where each female was crossed with each male. All fish had the same rearing history, had never experienced the natural environment, and only differed in levels of domestication or selection of their male parent:

- The Wild group is a progeny issued from the crossing of 13 Mediterranean wild (F0) dams with 20 Atlantic F0 sires: thus parents had not experienced any domestication or selection pressure (Millot et al. 2010).

- The Selected 1 group is a progeny issued from the crossing of the same 13 Mediterranean wild (F0) dams with 19 Atlantic F1 sires produced from a single generation with selection for growth (Millot et al. 2010).

- The Domesticated group is a progeny issued from the crossing of 6 dams with 6 sires, both Atlantic F1 domesticated, which had only been exposed to domestication pressure.

- The Selected 2 group is a progeny issued from the crossing of the same Atlantic F1 domesticated dams with 14 Atlantic F1 sires that had been subjected to two generation of selection for growth.

Important features of this method include:

- The wild parents had been in captivity for one to three years before they were used to breed the progenies.

- The F1 sires were the descendants of these same wild parents, and had completed an entire cycle of rearing (i.e., first generation of domestication) before they were chosen for reproduction.

- The choice of sires was made at the age of 20 months (400 g), and was carried out at random for the domesticated group, but among the 5\% longest for each selected group (i.e., first or second generation for the groups $\mathrm{Se}$ lected 1 or 2 , respectively).

Thus, the comparison of:

- Wild versus Selected 1 (Experiment 1) would show the effects of a first generation of domestication and selection for growth.

- Domesticated versus Selected 2 (Experiment 2) would show the effects of one pressure of selection for growth.

- Fish from Experiment 1 versus fish from Experiment 2 would show the effects of one more generation of domestication pressure.

The experiments were carried out with duplicates tank for each strain. The 4 tanks (400 L each) were supplied with semi-recirculated seawater, and all tanks were installed in the same room. For each tank, the flow rate was $4 \mathrm{~m}^{3} \mathrm{~h}^{-1}$ and the water renewal was $10 \%$ per day. Water temperature was maintained at $20.2 \pm 1.5^{\circ} \mathrm{C}$, oxygenation was above $90 \%$ of saturation in the water-outlet, and salinity was $22.3 \pm 3.3$. 
Table 1. Control and stress phases duration in both experiments.

\begin{tabular}{lccc}
\hline & Code & \multicolumn{2}{c}{$\begin{array}{c}\text { Duration } \\
\text { (number of days) }\end{array}$} \\
\cline { 3 - 4 } & & Exp. 1 & Exp. 2 \\
\hline Control phase & & 27 & 21 \\
control phase & P1 & 26 & 21 \\
Second control phase & P2 & & \\
\hline Phase following the: & & 24 & 21 \\
stress treatment & P3 & 35 & 21 \\
Second stress treatment & P4 & 35 \\
\hline
\end{tabular}

Water ammonia and nitrite compounds were measured every day, and were never above recommended levels for sea bass. Tanks were sheltered with black curtains, individually lit by a $120 \mathrm{~W}$ lamp, $90 \mathrm{~cm}$ above the water surface. The light regime was 16:8 LD (light onset at 06:00 h) with twilight transition periods of $30 \mathrm{~min}$. Fish were fed a commercial diet for sea bass (Neo Grower Extra Marin 4.0; www . aqua . legouessant . com) containing $45 \%$ crude protein and $20 \%$ lipid according to the manufacturer.

The first experiment (Exp. 1; Wild and Selected 1 groups) was realized over 112 days (5 May 2006-24 August 2006) with 240 fish (60 fish per tank, 120 fish per strain), and the second experiment (Exp. 2; Domesticated and Selected 2 groups) over 84 days (5 February 2008-28 April 2008) with 200 fish (50 fish per tank, 100 fish per strain). At the beginning of the study, fish were 14 and 12 months-old for Exp. 1 and 2 respectively. The Wild group weighed an average of $106 \pm 3 \mathrm{~g}$ (coefficient of variation $(\mathrm{CV})=32 \%, n=120$ fish), the Selected 1 group an average of $129 \pm 4 \mathrm{~g}(\mathrm{CV}=34 \%, n=120$ fish $)$, the Domesticated group an average of $72 \pm 3 \mathrm{~g}(\mathrm{CV}=30 \%$, $n=100)$, and the Selected 2 group an average of $89 \pm 4 \mathrm{~g}$ $(\mathrm{CV}=29 \%, n=100)$. Fish were again weighed to the nearest $\mathrm{mg}$ and measured for length to the nearest $\mathrm{mm}$ at 27 (D27), 53 (D53), 77 (D77), and 112 (D112) days after the beginning of Exp. 1; and 21 (D21), 42 (D42), 63 (D63), and 84 (D84) days after the beginning of Exp. 2. Experimental periods were defined as the period between two measuring days: P1 from D1 to D27 and from D1 to D21; P2 from D28 to D53 and from D22 to D42; P3 from D54 to D77, and D43 to D64; and P4 from D78 to D112, and D65 to D84 for Exp. 1 and Exp. 2 respectively (Table 1). All measures were done under anaesthesia using clove oil $(0.08 \%$ ) .

The feeder device included a screened type sensor (a metal rod protected by a PVC cylinder, Covès et al. 2006; Millot et al. 2008, 2009) and a control box. After each activation, fish were rewarded with 50 pellets; the feed dispensers, thus performed a mean distribution of 0.5 to $0.3 \mathrm{~g} \mathrm{~kg}^{-1}$ fish (Exp. 1), and 0.8 to $0.6 \mathrm{~g} \mathrm{~kg}^{-1}$ fish (Exp. 2) at the beginning and at the end of each test, respectively. Such a set up allowed the number, the date, and the hour of feed demand to be monitored in each tank.

Each fish was implanted with a PIT-tag (Passive Integrated Transponder) so that individual body mass and length could be monitored over time. Fish were placed under self-feeding conditions at D1, and food access was possible throughout the day $(24 \mathrm{~h})$, even during waste counts (10:00 to 11:00). Apparent feed consumption within each tank (feed amount dispensed minus wasted pellets collected in the sediment trap) was monitored daily. Triggering activity recordings were taken continuously for 112 and 84 days for experiments 1 and 2, respectively, except for the $24 \mathrm{~h}$ before and during fish handling ( 8 days out of the total for each experiment).

\subsection{Stress treatment}

After a first phase of rearing $(\mathrm{P} 1+\mathrm{P} 2)$, which represented the control phase of the experiment, acute stress events were applied twice between 10:00 and 12:00 on D53 and D77, and D42 and D64 for Exp. 1 and 2, respectively; P3 and P4 therefore represented the phases of post-stress treatment (Table 1). $\mathrm{P} 1+\mathrm{P} 2$ results were compared with post-stress results for all strains to look for stress-induced effects. Such an experimental design was chosen because all tanks were in the same room with the same water circuit, and disturbances to one tank were, therefore, unavoidably transmitted to adjacent tanks. The stressors consisted of draining the tank, and leaving the fish out of water for $1 \mathrm{~min}$ before being caught and anesthetised for weight and length measurement.

\subsection{Statistics}

To account for fish growth between the different defined periods, all feeding-related variables were considered relative to fish biomass. The variables chosen to measure the different performances were the following:

- the amounts of feed demanded (FD), food intake (FI) and food waste $(\mathrm{FW})$ ( $\mathrm{g}$ per $\mathrm{kg}$ of biomass present in the tank and per day). These variables were used to evaluate feeding behavior changes;

- the amount of feed demands per hour ( $\mathrm{g}$ per $\mathrm{kg}$ of fish biomass) was chosen to monitor the group feed demand rhythm and changes over time;

- the evolution over time of fish body mass ( $\mathrm{g}$ ), body condi-

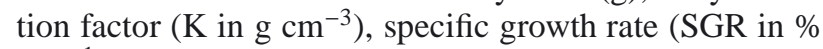
$\mathrm{day}^{-1}$ ), and feed efficiency (FE) was examined to find any growth pattern modifications, and to formulate hypotheses on changes in fish metabolic rate based on feed intake.

The calculated variables were obtained as follows:

- SGR $(\%$ body mass per day $)=100\left(\operatorname{Ln} M_{f}-\operatorname{Ln} M_{i}\right) t^{-1}$, $M_{f}$ and $M_{i}$ being the final and the initial body mass $(\mathrm{g})$ respectively, and $t$ the total number of days;

- $K\left(\mathrm{~g} \mathrm{~cm}^{-3}\right)=100 M L^{-3}, M$ and $L$ being the fish mass ( $\mathrm{g}$ ) and standard length $(\mathrm{cm})$, respectively;

- FE = (final fish biomass - initial fish biomass $) \times($ feed intake $)^{-1}$, Fish biomass is expressed in $\mathrm{kg}$.

All mean values were expressed with their standard error $( \pm \mathrm{SE})$.

For each experiment, data was checked for normality using the Shapiro-Wilk test, and for homogeneity of variances with the Bartlett's test; the experiments all complied with the assumptions of the parametric tests used thereafter. For the variables related to feeding behavior, fish body mass, body condition factors, and specific growth rate variables, a repeated 
A

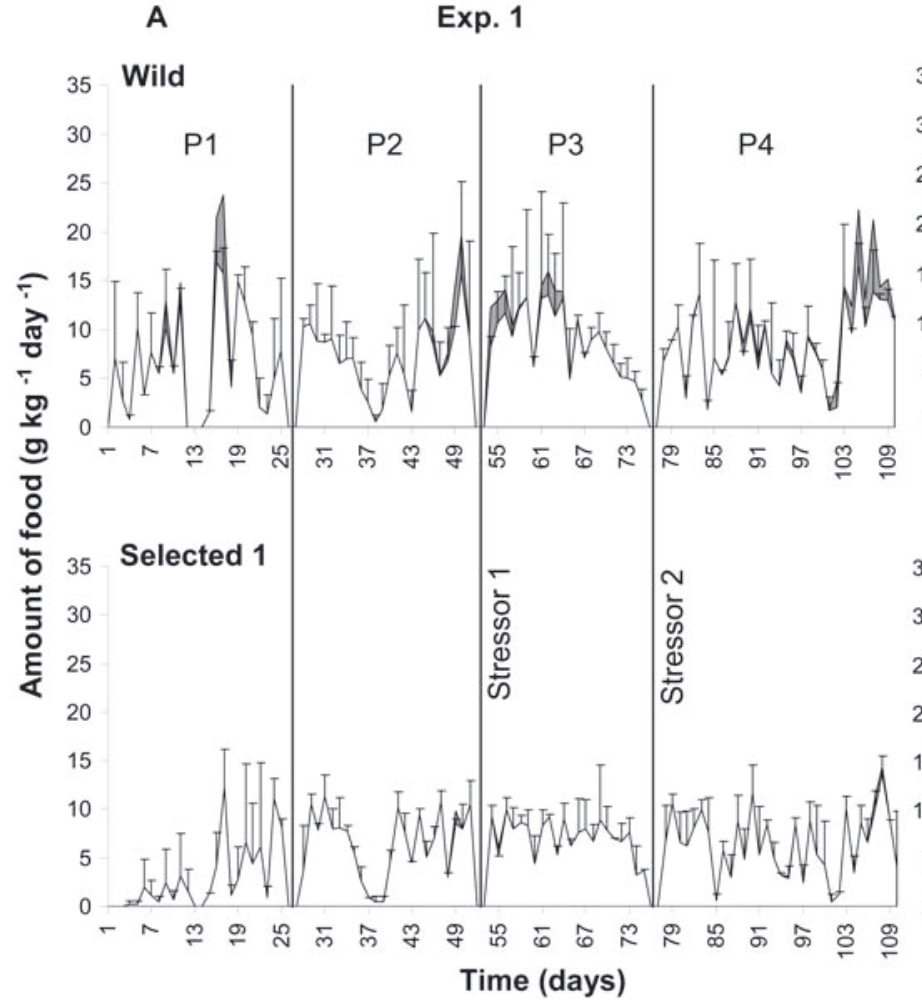

B

Exp. 2

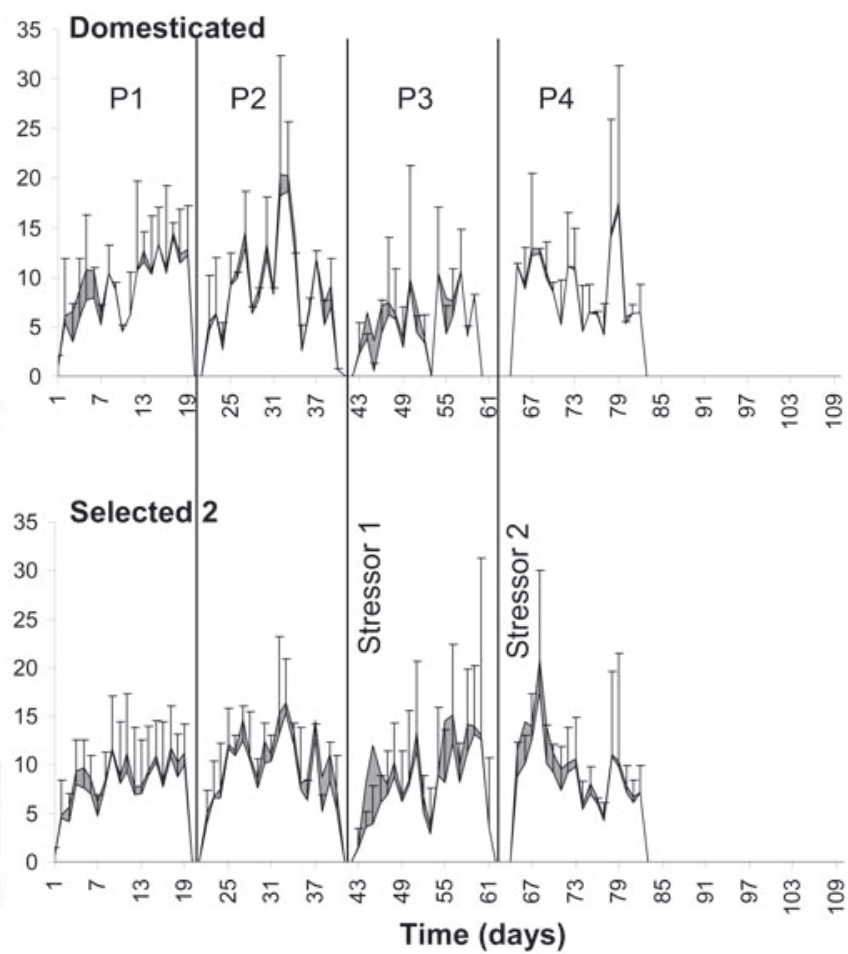

Fig. 1. Daily food intake and wastage. Daily mean $( \pm \mathrm{SE})$ intaken (white) and wasted (grey) food for 2 strains of sea bass in two experiments (Experiment 1 = Wild and Selected 1 (A), Experiment $2=$ Domesticated and Selected 2 (B)) during P1, P2, P3 and P4 periods. Stressors 1 and 2 represented the day when fish where submitted to acute stress event.

ANOVA was used to analyse the average differences between populations (fixed factor), periods (fixed factor), and tanks (random factor nested to population). The different periods considered here were: the control phases, P1 and P2; and the post-stress phases, P3 and P4. For the feed demand rhythm, a repeated ANOVA was used to assess the differences between populations (fixed factor), periods (fixed factor), hour (fixed factor), and tanks (random factor nested within population). The number of data for this variable corresponded to the number of recorded feeding days $(104$ or 76$) \times 24 \mathrm{~h} \times$ number of tank (4). Homogeneous groups were determined using the a posteriori Newman and Keuls test (Dagnélie 1975). For all tests, the significant threshold was $p<0.05$, and the analyses were performed using the Statistica software package (wWW.statsoft.com).

\section{Results}

During the experiment, some fish died for different reasons. Some of these individuals jumped out of the tanks, others died due to unidentified causes, but no mortality could be attributed to stress or anesthesia. These losses concerned: 1 Wild and 2 Selected 1 fish during P1; 1 Selected 1 fish during P3; and 2 Selected 1 fish during P4. These changes in the number of individuals were taken into account in all measured variables.

\subsection{Feed demand, intake and wastage over time}

The amount of feed demand and intake fluctuated highly from one day to another, and it was difficult to observe the immediate day-to-day stressor effect. However, in analysing the feeding behavior by period it was possible to observe variations over time.

The results of Exp. 1 (Fig. 1A) showed that the Wild groups learned how to use the device in only 2 days, contrary to the Selected 1 fish, which only began to correctly activate it after 14 days. This experiment also showed that, whatever the period, the Wild fish systematically demanded and ate more food than the Selected 1 fish $\left(F_{3,412}=15.2, p<0.001\right)$. During P1, Selected 1 demanded and ate entirely an average of $2.85 \pm 0.87 \mathrm{~g} \mathrm{~kg}^{-1} \mathrm{day}^{-1}$ while the Wild fish demanded on average $6.89 \pm 0.98 \mathrm{~g} \mathrm{~kg}^{-1} \mathrm{day}^{-1}$, ate $6.23 \pm 0.79 \mathrm{~g} \mathrm{~kg}^{-1} \mathrm{day}^{-1}$ and wasted $0.67 \pm 0.28 \mathrm{~g} \mathrm{~kg}^{-1} \mathrm{day}^{-1}$. During P2, demand and intake of food increased significantly for the Selected $1(+124 \%)$ while it stayed stable for the Wild. During P3, demand and intake of food remained stable for Selected 1 while it increased significantly for the Wild $(+25 \%)$. During P4, the amounts of FD and FI stayed stable for both groups.

The results of Exp. 2 (Fig. 1B) did not show any difference in learning ability between the Domesticated and Selected 2 fish, they both learned after about 2 days. This experiment highlighted that the Domesticated and Selected 2 demanded and ate the same amount of food during the whole experiment, except during P3 where the Selected 2 fish had a higher feeding activity than the Domesticated fish $\left(F_{3,280}=7.98, p<0.001\right)$. 
A

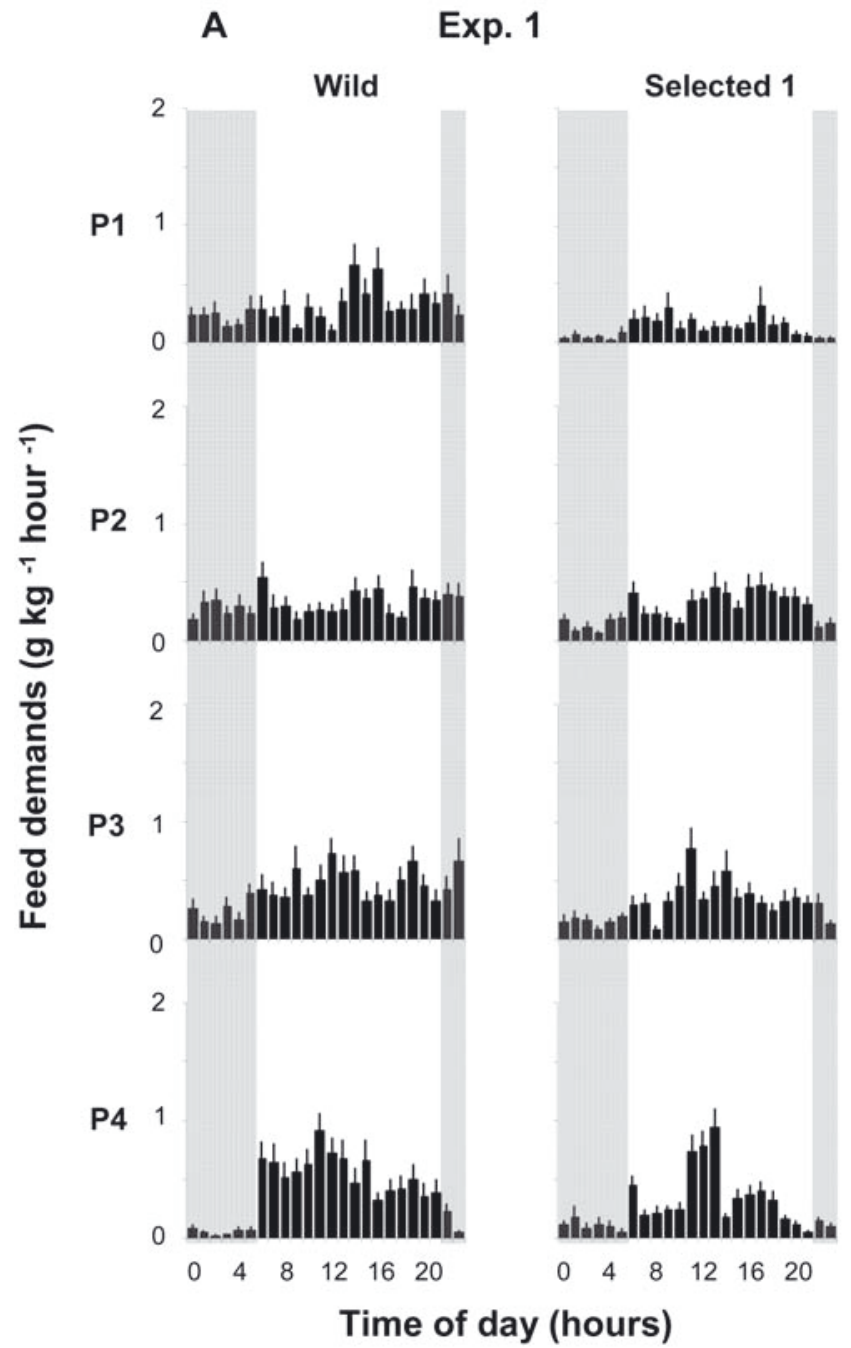

B

Exp. 2

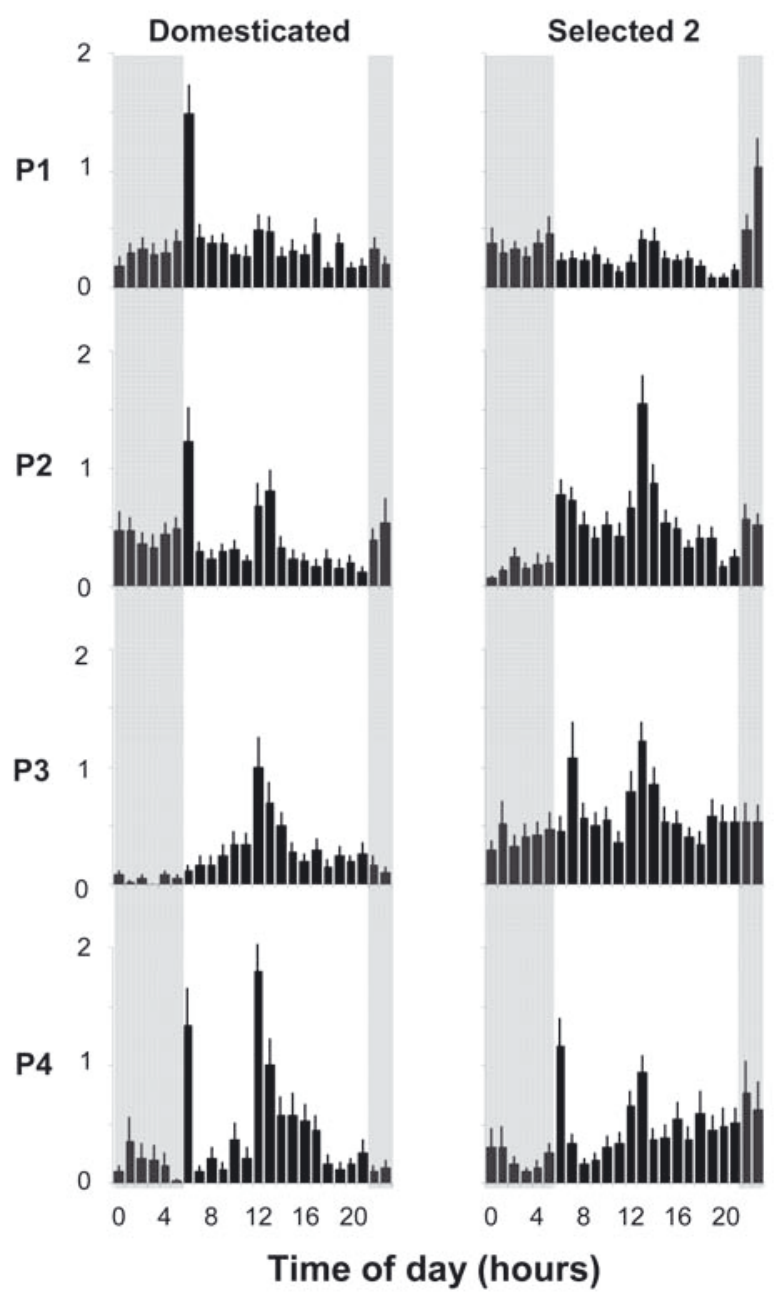

Fig. 2. Daily feeding rhythm. Pattern of daily mean $(+\mathrm{SE})$ feed demands per hour for 2 strains of sea bass in two experiments $($ Experiment $1=$ Wild and Selected 1 (A), Experiment 2 = Domesticated and Selected 2 (B)) during P1, P2, P3 and P4 periods. The grey boxes indicate the night period.

During P1, the Domesticated and Selected 2 groups demanded on average $8.57 \pm 0.67 \mathrm{~g} \mathrm{~kg}^{-1} \mathrm{day}^{-1}$, ate $7.58 \pm 0.58 \mathrm{~g} \mathrm{~kg}^{-1}$ day $^{-1}$ and wasted $0.99 \pm 0.20 \mathrm{~g} \mathrm{~kg}^{-1}$ day $^{-1}$. During P2, demand and intake of food increased significantly for Selected $2(+53 \%)$ while it stayed stable for the Domesticated group. During P2, Selected 2 fish also showed a slight increase of food wastage $\left(1.84 \pm 0.38 \mathrm{~g} \mathrm{~kg}^{-1} \mathrm{day}^{-1}\right)$. During P3, demand and intake of food remained stable for Selected 2 while it decreased significantly for the Domesticated group (-40\%). During this period, Selected 2 fish showed again, an increase of food wastage $\left(3.06 \pm 0.77 \mathrm{~g} \mathrm{~kg}^{-1} \mathrm{day}^{-1}\right)$. During P4, Selected 2 fish showed a slight decrease of FW, but the amounts of FD and FI stayed stable. In contrast, the Domesticated fish showed a stable FW, but an increase of $61 \%$ of food demanded and eaten.

\subsection{Daily rhythm of feeding activity}

The results of Exp. 1 (Fig. 2A) showed that the Wild and Selected 1 fish performed more feed demands during the day than during the night period. However, some differences appeared between groups over time $\left(F_{69,9090}=1.77, p<0.001\right)$. During P1, the Wild and Selected 1 fish performed respectively $73 \%$ and $88 \%$ of their feed demands during the day period. During P2, the Wild and Selected 1 fish still showed a diurnal feeding (98\% and $84 \%$ respectively) spread over the whole day. During P3, the highest percentages of feed demands were still diurnal for both groups (75\% for Wild and $81 \%$ for $\mathrm{Se}$ lected 1). During this period the Selected 1 fish presented a feeding peak at 11:00. During P4, the feeding rhythm for all groups was sharper. The Wild fish were more and more diurnal $(94 \%)$ and presented a feeding peak at 11:00 (10\% of feed demand; FD). The Selected 1 group performed $87 \%$ of their feed demands during the day period, especially from 11:00 to 13:00 (38\% FD).

The results of the Exp. 2 (Fig. 2B) showed that the Domesticated and Selected 2 fish performed more feed demands during the day than during the night period. However, some differences appeared between groups over time $\left(F_{69,6912}=2.74\right.$, $p<0.001)$. During P1, the Domesticated fish performed part 

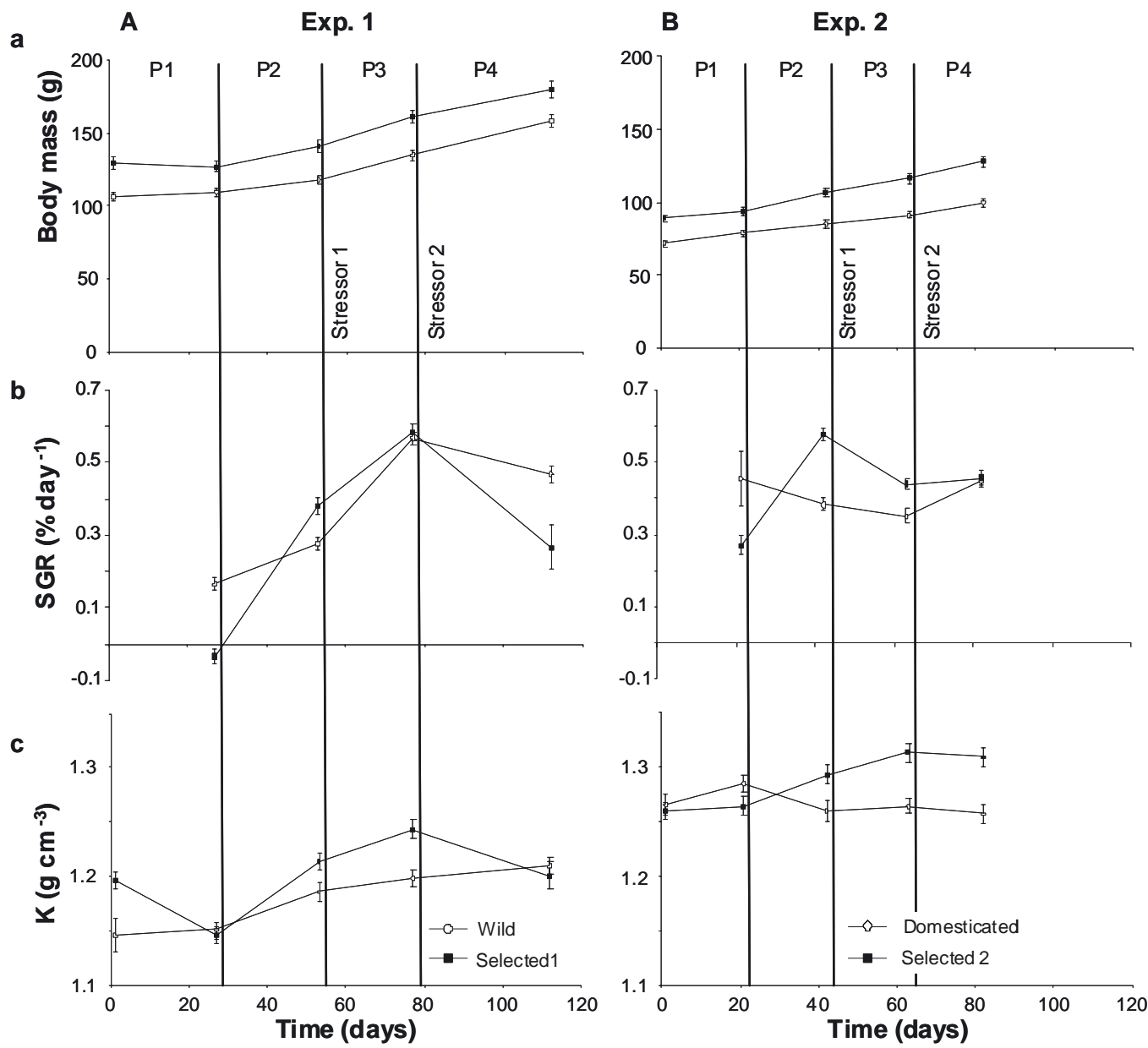

Fig. 3. Growth performance over time. Variations over time of mean $( \pm$ SE) body mass (a), specific growth rate, SGR (b) and body condition factor, $K$ (c) for Wild, Selected 1 (Experiment 1, A), Domesticated and Selected 2 (Experiment 2, B) sea bass strains during P1, P2:, P3 and P4 periods. Stressors 1 and 2 represented the day when fish where submitted to acute stress event.

of their feed demand during the day period $(73 \%)$ with a peak at 06:00, while the Selected 2 fish seemed more nocturnal $(51 \%)$ with a feeding peak at 23:00. During P2, the Domesticated and Selected 2 fish performed $62 \%$ (with a peak at 06:00) and $82 \%$ (with a peak at 13:00), respectively, of their feed demands during the day period. During P3, the highest percentages of feed demands were still diurnal for both groups (91\% for Domesticated and $74 \%$ for Selected 2). During this period the Domesticated fish presented a feeding peak at 12:00 and the Selected 2 fish at 07:00 and 13:00. During P4, the feeding rhythm for all groups was sharper. The Domesticated fish presented two main feeding peaks during the day period: at 06:00 (15\% FD) and at 12:00 (20\% FD). The Selected 2 fish continued to perform $75 \%$ of their feed demands during the day period with a peak at 06:00 (11\% FD) and one at 13:00 (9\% FD).

\subsection{Temporal variation in fish growth and feed efficiency}

The results of Exp. 1 (Fig. 3Aa) showed that during the whole experiment the Selected 1 fish presented a body mass around $18 \%$ higher than the Wild fish $\left(F_{1,1163}=80.8, p<\right.$ $0.001)$. Both groups were characterized by a stable body mass at D1 and D27, then a slight increase at D53 (+8\%), and finally a rapid increase at D77 and D112 $\left(+15 \% ; F_{4,1163}=63.8, p<\right.$ 0.001). Fish-specific growth rate was slower in the Selected 1 group than in the Wild group during P1 $(-0.03 \pm 0.02$ and $0.16 \pm 0.07 \%$ day $^{-1}$ respectively; Fig. $3 \mathrm{Ab}$ ). During P2, the Selected 1 showed a high SGR increase, while the Wild group was performed less well. After the first stress treatment (e.g., during P3), SGR increased for both groups. During P4, the Wild fish showed a stable SGR while it decreased by $55 \%$ for the Selected 1 group $\left(F_{3,933}=8.9, p<0.001\right)$.

At D1, the body condition factor $(K)$ of the Selected 1 group was higher than in the Wild population (Fig. 3Ac). At D27, the $K$ factor decreased greatly in the Selected 1 group and remained stable for the Wild fish. At D53, both groups showed a significant body condition factor increase. At D77, only the Selected 1 group showed a body condition factor increase $(+2 \%)$. Finally, at D112, the $K$ factor stayed stable for the Wild group and decreased for the Selected 1 fish $(-3 \%$; $\left.F_{4,1163}=4.2, p<0.01\right)$. The Wild and Selected 1 populations had similar feed efficiency (FE) during the whole experiment 
$\left(F_{3,8}=1.15, p=0.38\right)$. However, the FE values varied over time; it was of $-0.33 \pm 0.46$ during $\mathrm{P} 1$, then increased during $\mathrm{P} 2(0.52 \pm 0.07)$ and P3 $(0.82 \pm 0.18)$, and finally returned to $0.51 \pm 0.04$ during $\mathrm{P} 4$.

The results of Exp. 2 (Fig. 3Ba) showed that the Selected 2 fish presented a body mass of around $25 \%$ more than the Domesticated fish during the whole experiment $\left(F_{1,980}=151.5\right.$, $p<0.001)$. Both groups were characterized by a constant increase of body mass between each measuring day $(+9 \%$; $\left.F_{4,980}=47.5, p<0.001\right)$. Fish-specific growth rate was slower in the Selected 2 group than in the Domesticated group during $\mathrm{P} 1\left(0.27 \pm 0.03\right.$ and $0.45 \pm 0.07 \% \mathrm{day}^{-1}$ respectively; Fig. 3Bb). During P2, Selected 2 showed a high SGR increase while the Domesticated group was characterized by a SGR decrease of 17\%. After the first stress treatment (e.g., during P3), Selected 2 fish showed a SGR decrease of $24 \%$ while it stayed stable for the Domesticated ones. During P4, the Selected 2 fish showed a stable SGR while SGR increased by $29 \%$ for the Domesticated group $\left(F_{3,784}=42.2, p<0.001\right)$.

At D1, there was no difference in body condition factor $(K)$ between the Domesticated and Selected 2 groups (Fig. 3Bc). At D21, the $K$ factor was still stable for both groups. At D42, Selected 2 fish showed a significant body condition factor increase, but this remained stable for the Domesticated ones. Finally, at D63 and D84, the $K$ factor was still stable for both groups $\left(F_{4,980}=7.9, p<0.001\right)$.

The Domesticated and Selected 2 populations had similar feed efficiency (FE) during the whole experiment $\left(F_{3,8}=1.47\right.$, $p=0.29)$ without variation over time. Their average FE value was $0.59 \pm 0.06$.

\section{Discussion}

\subsection{Control phase}

According to the results of the first study experiment, it seemed that a first generation of domestication and selection did not improve the capacity of the fish to learn how to use the self-feeder. Indeed, at the beginning of this experiment, fish were naive about using the self-feeder; the Wild groups then learned how to use the device in only 2 days, in contrast to the Selected 1 fish, which only began to activate it correctly after 14 days. This early period was thus one of food deprivation and was characterised by a slight loss of fish body mass, a negative growth rate, and a decrease in $K$ factor for this population. The second experiment did not show any difference in learning ability between the Domesticated and Selected 2 fish. Indeed, despite the fact that fish were also naïve when faced with the self-feeder, both groups of fish started to use the device after only 2 days. Thus, it seemed that the selection process did not influence fish learning ability. Nevertheless, the comparison between the two experiments showed that a second generation of domestication might improve fish adaptation toward self-feeder triggering for the selected fish.

During the second part of the control period, the Selected 1 group, which presented the lowest SGR at the beginning of Exp. 1, showed a high increase of its growth performance. The fish growth increase was mainly attributable to an increase in feed intake $(+124 \%)$ and to an increase in feed efficiency, which corresponded to the growth compensatory phenomenon as defined by Jobling (1994). However, the feed efficiency was the same for the Wild and Selected 1 strains. The same result was observed for the Selected 2 fish in Exp. 2 (+53\% of feed intake) with the same feed efficiency between domesticated and selected strains. Thus, the better growth performance of Selected 1 and 2 fish could be explained by their cumulative feed intake, and as observed by Mambrini et al. (2004) on Salmo trutta L., feed efficiency was not affected by the selection processes. The level of fish domestication also did not seem to influence the compensatory growth capacities of sea bass.

The rhythm of feeding activity indicated that sea bass did not feed continuously during the day. They displayed a diurnal feeding behavior, with an important peak of feed demands at dawn (06:00) and at 13:00, for fish issued from the second generation of domestication and selection. This result was in accordance with the observation of Mambrini et al. (2004) on S. trutta, which showed that feeding rhythm was affected significantly by the strain, the peak of feeding being more pronounced with fish domestication and selection level.

\subsection{Post-stress phase}

Fish handling, associated with capture and confinement, is generally considered to alter behavior (Pickering et al. 1982; Mesa 1994; Olla et al. 1995). The most common change in fish is a reduction of the feeding activity during the stress period (Pickering et al. 1991; Farbridge and Leatherland 1992; Pankhurst and Van der Kraak 1997) associated with a reduction in growth rate (Pickering and Stewart 1984; McCormick et al. 1998; Liebert and Schreck 2006), and a probable increase in energy demand, and thus metabolic rate, as shown by Barton and Schreck (1987), Wendelaar Bonga (1997) and Pankhurst and Van Der Kraak (1997). In our studies, none of the sea bass strains presented such behavioral patterns after acute stress treatments, but instead showed different reactions.

In Exp. 1, the Wild fish appeared less negatively affected by the stressor (showing an increase in feed demand and SGR) than the Selected 1 fish, which were characterized by an increase in SGR, but a stable feed intake. According to McCarthy and Siegel (1983), such a phenomenon could result from an increasing amount of energy allocated to growth versus maintenance cost, and thus could be interpreted as rapid stress adaptation. The second stress treatment seemed to have no effect on the Wild fish. Indeed, these fish ate the same amount of food and grew at the same rate as during the preceding period. In contrast, the Selected 1 fish showed a decrease in SGR, and a stable feed intake during this period. According to these results, it seems that a first generation of domestication and selection for growth do not improve the fish stress adaptability.

In Exp. 2, the Domesticated fish also seemed affected by the first stressor, but capable of rapid adaptation. Indeed, they showed a decrease in feed intake and a stable SGR. As for the Selected 1 fish, such phenomena could result from an increasing amount of energy allocated to growth versus maintenance cost. The Selected 2 fish seemed more affected by the first stress treatment. This population showed a high SGR decrease 
$(-24 \%)$, and the same feed intake, but a significant increase of wasted food, which was already identified as an indicator of stress level by Millot et al. (2008). After the second stress treatment, the Domesticated group showed the same feed intake and SGR as observed before the stress treatments. These results could be interpreted as a total stress recovery. The $\mathrm{Se}$ lected 2 fish presented some recovery indicators such as a decrease of food wastage, but still kept a constant SGR. Also, for this experiment, selection for growth process did not seem to improve fish stress adaptability. The comparison of the results of these two studies showed that the domestication process did not seem to influence fish stress response.

The post-stress treatment period was also characterized by feeding rhythm changes. Indeed, in the first experiment, the Wild fish group presented an increasingly diurnal feeding pattern over time, reaching $94 \%$ of their feed demand during the day period at the end of the experiment, and the Selected 1 fish showed a feeding activity progressively restricted to the 11:00-13:00 period. This preference for an increasingly diurnal feeding over time was also observed for these two populations when they were exposed to frequent, repeated, acute stress (Millot et al. 2010). In the second experiment, the Selected 2 fish concentrated their feeding activity on two peaks: at 06:00 and at 13:00. The Domesticated fish presented a particularly interesting feeding rhythm change. Before the stress treatment, this population was characterised by a feeding peak at 06:00, but after the first acute stress treatment this feeding peak completely disappeared and resumed after the second stress treatment for the Domesticated fish, indicating a full recovery.

In conclusion, and according to the results of these studies, application of two acute stress treatments at three-week intervals, modified fish feeding behavior and growth performance. These strain comparisons also suggest that the domestication process promotes fish environmental adaptation (i.e. self-feeder use) and that fish issued from selection for growth processes seemed to have different adaptation abilities, which despite post-stress behavioral modifications ultimately led to better growth. Considering the economic importance of fast fish growth in the aquaculture industry, it seems that the domestication and selection processes could be even more profitable if meal timing and quantity could be flexible, and thus respect fish needs in relation to environmental constraints; it would, hence, potentially enhance fish welfare under culture conditions. An additional option would be to use stress tolerance criteria as selection objectives. Nevertheless, to improve our understanding the effects of domestication and selection processes, we recommend that further experiments should be carried out on fish issued from subsequent generations of these lines.

Acknowledgements. We wish to thank D. Leguay and P. Pineau for their technical help. We also thank H. McCombie-Boudry for editing the English of this manuscript. This work was performed as part of the Integrated Research Project SEAFOODplus, contract no. FOODCT-2004-506359 and STREP FASTFISH, contract No. 022720. The funding of this work by the European Union and by the county council of Charente Maritime is gratefully acknowledged. This study was conducted under the approval of the Animal Care Committee of France under the official licence of M.L. Bégout (17-010).

The fish that were tested here were issued from the COMPETUS project, funded by Ardag Red Sea Mariculture (Eilat, Israel), Ecloserie Marine de Gravelines (Gravelines, France), Les Poissons du Soleil (Balaruc, France), Tinamenor SA (Pesues, Cantabria, Spain), Viveiro Vilanova (Vila Nova de Milfontes, Portugal) and the European Union (project COOP-CT-2005-017633).

\section{References}

Ashley P.L., 2007, Fish welfare: current issues in aquaculture. Appl. Anim. Behav. Sci. 104, 199-235.

Balm P.H.M., 1997, Immune-endocrine interactions. In: Iwana G., Pickering A., Sumpter J., Schreck C. (Eds.), Fish Stress and Health in Aquaculture. Cambridge University Press, Cambridge, pp. 195-222.

Barton B.A., 2002, Stress in fishes: a diversity of responses with particular reference to changes in circulating corticosteroids. Integr. Comp. Biol. 42, 517-525.

Barton B.A., Schreck, C.B., 1987, Metabolic cost of acute physical stress in juvenile steelhead. Trans. Am. Fish. Soc. 116, 257-263.

Barton B.A., Schreck C.B., Barton L.D., 1987, Effects of chronic cortisol administration and daily acute stress on growth, physiological conditions, and stress responses in juvenile rainbow trout. Dis. Aquat. Org. 2, 173-185.

Broom D.M., 1988, The concept of stress and welfare. Rec. Méd. Vét. $164,715-721$.

Chatain B., 1994, Estimation et amélioration des performances zootechniques de l'élevage larvaire de Dicentrarchus labrax et de Sparus auratus. Thèse Dr. Etat, Univ. Aix-Marseille II.

Conte F.S., 2004, Stress and the welfare of cultured fish. Appl. Anim. Beh. Sci. 86, 205-223.

Contreras-Sanchez W.M., Schreck C.B., Fitzpatrick M.S., Pereira C.B., 1998, Effects of stress on the reproductive performance of rainbow trout (Oncorhynchus mykiss). Biol. Reprod. 58, 439447.

Covès D., Beauchaud M., Attia J., Dutto G., Bouchut C., Bégout Anras M.-L., 2006, Long-term monitoring of individual fish triggering activity on a self-feeding system: an example using European sea bass (Dicentrarchus labrax). Aquaculture 253, 385-392.

Dagnélie P., 1975, Théorie et méthodes statistiques. In: Applications agronomiques, Vol. 2. Presses Agronomiques de Gembloux, Gembloux.

Dupont-Nivet M., Vandeputte M., Vergnet A., Merdy O., Haffray P., Chavanne H., Chatain B., 2008, Heritabilities and GxE interactions for growth in the European sea bass (Dicentrarchus labrax L.) using a marker-based pedigree. Aquaculture 275, 81-87.

Einarsdottir I.E., Nilssen K.J., Iversen M., 2000, Effects of rearing stress on Atlantic salmon (Salmo salar L.) antibody response to a non-pathogenic antigen. Aquac. Res. 31, 923-930.

Farbridge K.J., Leatherland J.F., 1992, Plasma growth hormone levels in fed and fasted rainbow trout (Oncorhynchus mykis) are decreased following handling stress. Fish Physiol. Biochem. 10, 67-73.

Huntingford F.A., Adams C., Braithwaite V.A., Kadri S., Pottinger T.G., Sandoe P., Turnbull J.F., 2006, Current issues in fish welfare. J. Fish Biol. 68, 332-372.

Huntingford F.A., Kadri S., 2008, Welfare and fish. In: Branson E.J. (Ed.), Fish welfare. Blackwell Publishing Ltd, Oxford. 
Jobling M., 1994, Fish Bioenergetics. Chapman and Hall, London.

Liebert A.M., Schreck C.B., 2006, Effects of acute stress on osmoregulation, feed intake, IGF-1, and cortisol in yearling steelhead trout (Oncorhynchus mykiss) during seawater adaptation. Gen. Comp. Endocr. 148, 195-202.

Mazeaud M.M., Mazeaud F., Donaldson E.M., 1977, Primary and secondary effects of stress in fish: some new data with a general review. Trans. Am. Fish. Soc. 106, 201-212.

McCarthy J.C., Siegel P.B., 1983, A review of genetical and physiological effects of selection in meat-type poultry.Anim. Breed. Abstr. 51, 87-94.

Mambrini M., Sanchez M.-P., Chevassus B., Labbé L., Quillet E., Boujard T., 2004, Selection for growth increases feed intake and affects feeding behaviour of brown trout. Livest. Prod. Sci. 88, 85-98.

McCormick M.I., 1998, Behavioural induced maternal stress in a fish influences progeny quality by a hormonal mechanism. Ecology 79, 1873-1883.

McCormick M.I., 1999, Experimental test of the effect of maternal hormones on larval quality of a coral reef fish. Oecologia 118, 412-422.

McCormick S.D., Shrimpton J.M., Carey J.B., O’Dea M.F., Sloan K.E., Moriyama S., Björnsson B.T., 1998, Repeated acute stress reduces growth rate of Atlantic salmon parr and alters plasma levels of growth hormone, insulin-like growth factor I and cortisol. Aquaculture 168, 221-235.

Mesa M.G., 1994, Effects of multiple acute stressors on the predator avoidance ability and physiology of juvenile chinook salmon. Trans. Am. Fish. Soc. 123, 786-793.

Millot S., Bégout M.-L., Person-Le Ruyet J., Breuil G., Di-Poï C., Fievet J., Pineau P., Roué M., Sévère A., 2008. Feed demand behavior in sea bass juveniles: effects on individual specific growth rate variation and health (inter-individual and inter-group variation). Aquaculture 274, 87-95.

Millot S., Bégout M.L., 2009, Individual fish rhythm directs group feeding: a case study with sea bass juveniles (Dicentrarchus labrax) under self-demand feeding conditions. Aquat. Liv. Resour. 22, 363-370.

Millot S., Péan S., Leguay D., Vergnet A., Chatain B., Bégout M.L., 2010, Evaluation of behavioral changes induced by a first step of domestication or selection for growth in the European sea bass (Dicentrarchus labrax): a self-feeding approach under repeated acute stress. Aquaculture 306, 211-217.

Olla B.L., Davis M.W., Schreck C.B., 1995, Stress-induced impairment of predator evasion and non-predator mortality in Pacific salmon. Aquac. Res. 26, 393-398.
Pankhurst N.W., Van der Kraak G., 1997, Effects of stress on reproduction and growth. In: Iwana, G., Pickering, A., Sumpter, J., Schreck, C. (Eds.) Fish Stress and Health in Aquaculture Cambridge University Press, Cambridge. pp. 73-94.

Parker N.C., 1984, Chronobiologic approach to aquaculture. Trans. Am. Fish. Soc. 113, 545-552.

Pickering A.D., 1992, Rainbow trout husbandry-management of the stress response. Aquaculture 100, 125-139.

Pickering A.D., Stewart A., 1984, Acclimation of the interregnal tissue of the brown trout Salmo trutta L., to chronic crowding stress. J. Fish Biol. 24, 731-740.

Pickering A.D., Pottinger T.G., Christie P., 1982, Recovery of the brown trout, Salmo trutta L., from acute handling stress: a timecourse study. J. Fish Biol. 20, 229-244.

Pickering A.D., Pottinger T.G., Sumpter J.P., Carragher J.F., Le Bail P.Y., 1991, Effects of acute and chronic stress on the levels of circulating growth hormone in the rainbow trout, Oncorhynchus mykiss. Gen. Comp. Endocr. 83, 86-93.

Pottinger T.G., 2003, The selection of trout for high and low responsiveness to stress: progress and prospects. Trout News, CEFAS $36,14-16$.

Pottinger T.G., Pickering A.D., 1997, Genetic basis to the stress response: selective breeding for stress-tolerant fish. In: Iwana G., Pickering A., Sumpter J., Schreck C. (Eds.), Fish Stress and Health in Aquaculture. Cambridge University Press, Cambridge, pp. 171-193.

Price E.O., 1984, Behavioural aspects of animal domestication. Quart. Rev. Biol. 59, 1.

Schreck C.B., Contreras-Sanchez W., Fitzpatrick M.S., 2001, Effects of stress on fish reproduction, gamete quality, and progeny. Aquaculture 197, 3-24.

Spieler R.E., 1977, Diel and seasonal changes in response to stimuli: a plague and a promise for mariculture. J. World Maricult. Soc. 8, 865-873.

Vandeputte M., Dupont-Nivet M., Haffray P., Chavanne H., Cenadelli S., Parati K., Vidal M.-O., Vergent A., Chatain B., 2009, Response to domestication and selection for growth in the European sea bass (Dicentrarchus labrax) in separate and mixed tanks. Aquaculture 286, 20-27.

Wedemeyer G.A., Barton B.A., McLeay D.J., 1990, Stress and acclimation. In: Schreck C.B., Moyle PB (Eds.), Methods for Fish Biology. American Fisheries Society, Bethesda, Maryland, pp. 451-489.

Wendelaar Bonga S.E., 1997, The stress response in fish. Physiol. Rev. 77, 591-625. 